\title{
HACIA UN MOBILIARIO MODERNO: DISEÑO DE MOBILIARIO PARA LA NUEVA VIVIENDA EN EL PERIODO DE ENTREGUERRAS TOWARDS A MODERN FURNITURE: FURNITURE DESIGN FOR NEW HOUSING BETWEEN THE TWO WORLD WARS
}

María Villanueva Fernández* Héctor García-Diego Villarías Universidad de Navarra

\section{Resumen}

Tras la I Guerra Mundial tuvieron lugar un conjunto de cambios sociales que transformaron sensiblemente los hábitos de vida. Como consecuencia la estructura de la vivienda fue modificando inevitablemente el diseño de su mobiliario. Las nuevas tipologías habitacionales se idearon en reducidas dimensiones, tratando de integrar los servicios básicos necesarios para el disfrute de la vida 'moderna'. En este desarrollo, la experimentación fue cardinal para el amueblamiento de los nuevos espacios mínimos, dando lugar a nuevos modelos de mobiliario transformable $\mathrm{y}$ de uso polivalente que permitían un mejor aprovechamiento del espacio. Este artículo pretende mostrar algunos proyectos de arquitectos europeos que, asumiendo los nuevos cambios sociales, plantearon muebles de gran versatilidad que evidenciaban la evolución del equipamiento interior de la vivienda hacia un mobiliario moderno.

Palabras Clave: diseño, mobiliario, cambios sociales, espacios multifuncionales, entreguerras.

\section{Abstract}

After IWW there were a number of social changes that significantly transformed the lifestyle and, as a result of it, the structure of the house. This transformation of interior space inevitably provoked a deep modification in the design of furniture. The new housing typologies were designed in small sizes, trying to integrate the basic services necessary for the enjoyment of 'modern' life. In this development, In this development, research was cardinal for furnishing the new minimum space, leading to new models of transformable multi-purpose furniture and allowing a better utilization of space. This article shows some works of European architects who, assuming the new social raised versatile furniture which showed the way in which the interior design turned into modern furniture. 
Keywords: design, furniture, social changes, multifunctional spaces, interwar period.

Ya en la primera década del siglo XX la organización social se estaba conformando en torno a una nueva clase media con costumbres y objetivos que distaban considerablemente de las tradiciones de la sociedad del siglo anterior. Aunque las grandes revoluciones comenzaron a gestarse antes de la I Guerra Mundial, no fue hasta 1918 cuando se hicieron perceptibles dichos cambios, transformando de forma considerable el interior de las viviendas. Fue a partir de entonces cuando afloraron nuevas propuestas de diseño de mobiliario para equipar las distintas variaciones tipológicas originadas por los cambios sociales en el periodo entreguerras, especialmente, con el surgimiento de nuevas formas de vida.

Aquellos proyectos, en ocasiones, habían sido alumbrados por arquitectos y diseñadores de mobiliario que hoy son escasamente reconocidos en los manuales de arquitectura y/o diseño pero que, sin embargo, plantearon muebles de una alta versatilidad, recogiendo las propuestas precedentes de otros arquitectos, de indudable fama, como Aldof Loos o Le Corbusier. Dentro de este elenco de creadores se encuentran Paul Bry y Reudenauer, Pierre Chareau, las hermanas Gémes, Jean Ginsberg y Bertold Lubetkin, Rudolf Fränkel y Ernst Dobler cuyos proyectos protagonizaron las páginas de revistas internacionales y nacionales. Entre estas últimas destacan, en el ámbito nacional, Arquitectura, Nueva Formas, Viviendas y Obras cuyos contenidos acercaban a los españoles las propuestas europeas para la nueva vivienda moderna.

De hecho, estas mismas fuentes de información permiten hoy descubrir y poner en valor el trabajo de estos arquitectos europeos a partir de proyectos concretos, así como acercar al lector sus figuras, valorando la importancia de estos casos y contextualizando sus aportaciones en el panorama del periodo de entreguerras. A través de los proyectos de diseño de mobiliario de este grupo de arquitectos europeos, difundidos en las publicaciones periódicas citadas, es posible analizar los cambios producidos en la vivienda, originados por las modificaciones sociales, a través de sus aportaciones al diseño de mobiliario.

\section{Nuevas formas de vida, nuevas tipologías de vivienda}

Uno de los cambios que contribuyeron a reformar la estructura del hogar fue la incorporación de la mujer al ámbito laboral. El conflicto bélico iniciado en 1914 propició que muchas mujeres participaran directamente en la contienda, realizando trabajos que antes habían sido desempeñados por hombres ${ }^{1}$. Lo que comenzó siendo un mero sometimiento a las necesidades de la Gran Guerra, se convirtió paulatinamente en la adaptación a una nueva forma de vivir. Según explica Morales: "En esta Primera Guerra Mundial, la mujer hubo de desempeñar, no sólo el papel de consoladora, de enfermera, de restañadora de 
heridas, físicas y morales, que su misión pasiva y conservadora le asigna desde el principio de los siglos, sino también el de colaboradora y en proporción nunca soñada, el de sustituto del hombre." ${ }^{2}$

Cuando llegó la paz, muchas mujeres se incorporaron a la vida laboral, de modo que no renunciaron a la libertad de la que habían disfrutado durante la guerra. La extensión del trabajo de las mujeres, su acceso a muchas de las funciones masculinas y la igualación de sus derechos civiles propiciaron cambios significativos en las formas de vivir, afectando directamente a la distribución y configuración de la vivienda que debía adaptarse a los nuevos hábitos de existencia diaria.

La esencia de estas ideas fue recogida en 1924 por el conocido arquitecto alemán Bruno Taut en su libro Die neue Wohnung: die Frau als Schöpferin (El nuevo apartamento: la mujer como creadora) ${ }^{3}$. En este texto el arquitecto explicaba que el origen del cambio en el interior dependía en gran medida del papel de la mujer en el hogar. La revista Arquitectura ${ }^{4}$ se hacía eco de las palabras de Taut: "Dedicado a las mujeres. El péndulo de los siglos está en su punto más bajo para volver a subir. Lo que hasta ahora fue negación es afirmación con una nueva meta. La mujer estuvo hasta el momento de espaldas a la casa y ahora se vuelve hacia ella. De la crítica desnuda sale la nueva creación. No es la crítica un reproche, sino mirada hacia el nuevo camino"; y añadía: "el arquitecto piensa, la mujer decide" 5 .

De esta relación que se estableció entre arquitecto y mujer surgieron nuevos espacios adaptados a la nueva vida laboral de las mujeres. Uno de los proyectos resultantes de esta investigación fue el proyecto del arquitecto alemán Ernst Dobler que la revista Viviendas tituló "Decoración de una vivienda dormitorio para una dama"6. Dobler trató de dar respuestas a las necesidades de la nueva mujer trabajadora mediante el diseño de una vivienda tipo. El hecho de que se plantease este diseño interior para 'la mujer trabajadora' resultaba especialmente 'moderno'; sin embargo, la propuesta de Dobler desvelaba que todavía existían diferencias marcadas entre géneros; especialmente, en cuanto a la tendencia a recargar el interior con telas estampadas y mobiliario de formas curvas.

También el arquitecto Reudenauer profundizó en el estudio de ámbitos para la 'nueva' mujer y sus necesidades. Planteó, a través del "Cuarto de estar para una dama" y del "Salón para la directiva de una fábrica"7, reflexionar sobre el espacio que precisaba el sector femenino en la vivienda. Estos proyectos materializaban los primeros signos de igualdad en la arquitectura residencial de forma más clara. Además, en el segundo caso, el arquitecto combinó tanto la madera como el tubo de acero curvado como muestra de modernidad, tratando de ofrecer una nueva imagen innovadora del hogar así como de la mujer. 

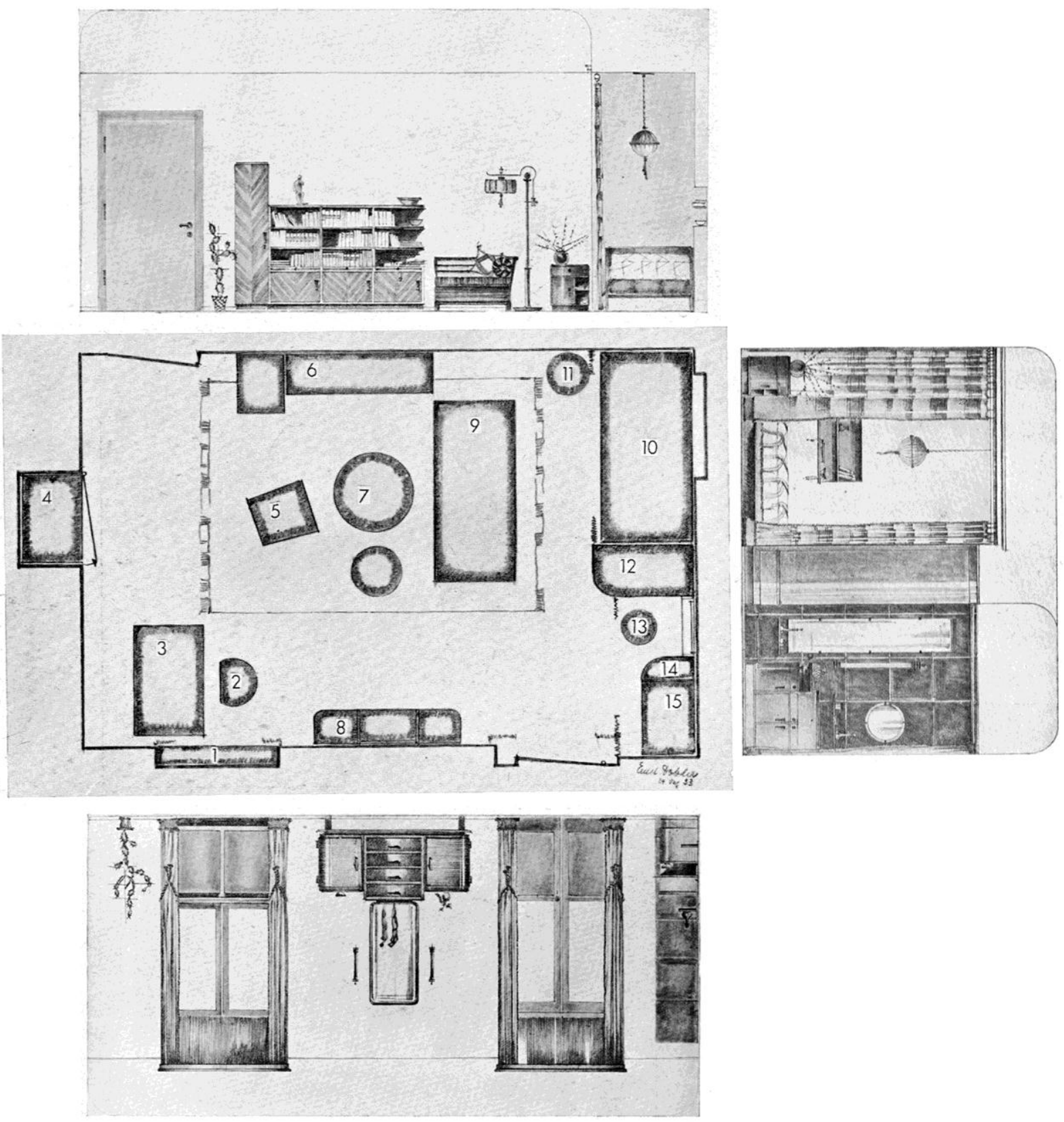

Fig. 1. Fotomontaje elaborado por la autoría con los planos del proyecto la "Vivienda dormitorio para una dama" dibujados por Ernst Dobler. Fuente: Nuevas Formas. Revista de arquitectura y decoración, nº, Madrid, $1935 / 36$. 

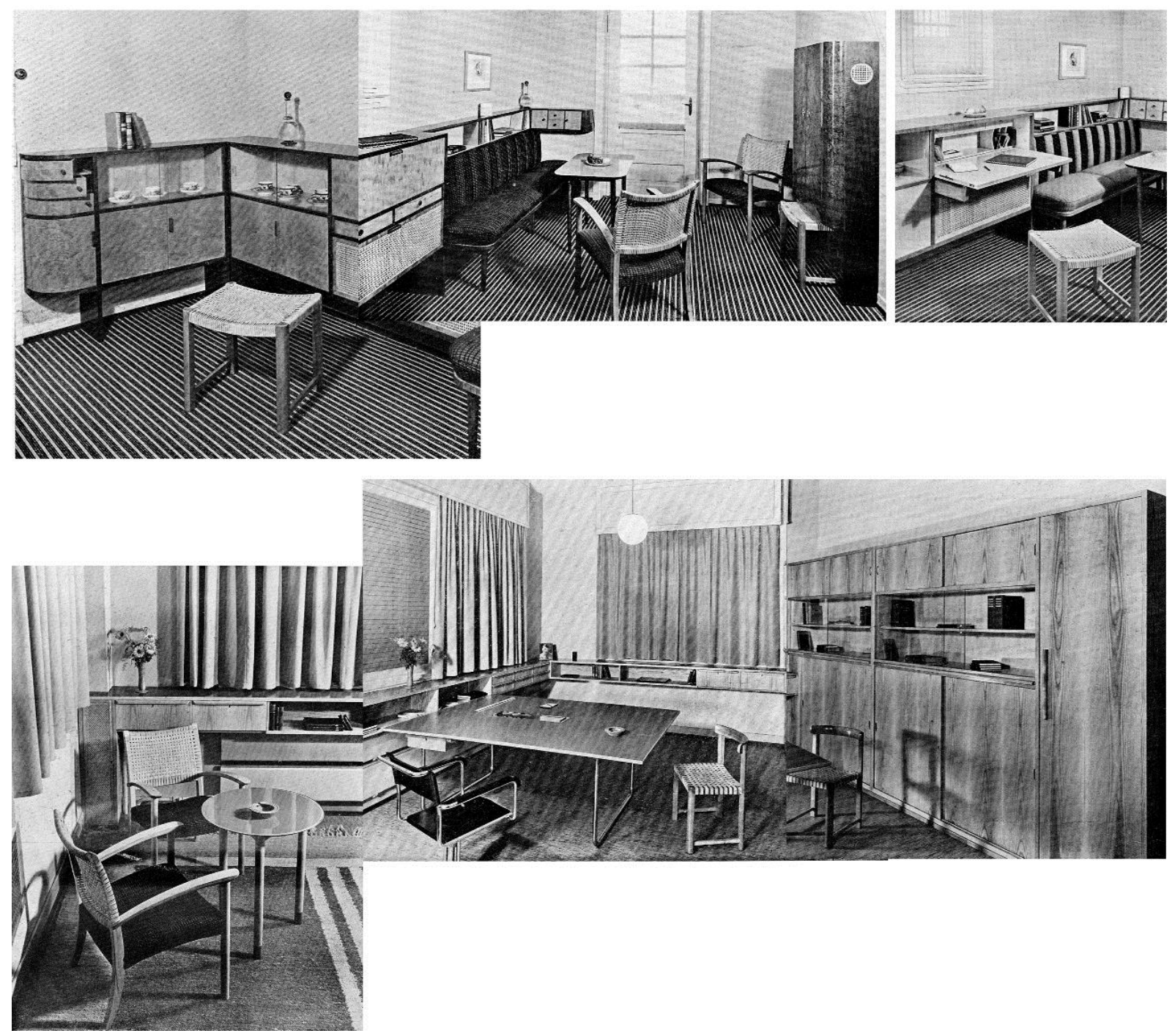

Fig. 2. Fotomontajes elaborados por la autoría a partir de imágenes de los proyectos "Cuarto de estar para una dama" (arriba) y "Salón para la directiva de una fábrica" (abajo) del arquitecto A.C. Reudenauer. Fuente: Nuevas Formas. Revista de arquitectura y decoración, nº, Madrid, 1935/36.

Estos cambios motivaron modificaciones en la estructura de la vivienda. El hogar ya no era teóricamente un lugar 'custodiado' por la mujer durante todo el día, sino que era un espacio habitado únicamente al regreso de la jornada laboral. Esta evolución obligaba a reconsiderar la anatomía de la vivienda, repensando espacios ahora no tan necesarios - como las estancias para recibir invitados-, estudiando las circulaciones, necesidades y distribuciones desde una óptica más funcional, y diseñando el mobiliario según parámetros prácticos, que ayudasen a hacer la vida más sencilla tras un largo e intenso día de trabajo.

En 1930, poco tiempo antes de este último proyecto, Walter Gropius, conocido arquitecto y primer director de la Bauhaus, abordó en el III Congreso Internacional de Arquitectura Moderna (CIAM), celebrado en Bruselas, la cuestión de la incorporación de la mujer al trabajo para apoyar la construcción de las viviendas en altura: “...la mujer moderna, no sólo está en el camino de la independencia por necesidad sino también por un impulso interior, y quiere ser 
relevada del trabajo doméstico para participar del trabajo común. El edificio de muchos pisos le ofrece más oportunidades que la casa de propiedad, sobre todo si está provisto de servicios domésticos centralizados"8. Un año antes Gropius ya había reflexionado sobre la situación social en relación al habitar en su texto 'Los fundamentos sociológicos de la vivienda mínima'9 presentado en 1929 en Frankfurt a la edición de CIAM. En este documento el arquitecto alemán realizó un análisis pormenorizado de la evolución de la sociedad en términos de estructura familiar, económica y laboral.

A estas variaciones en la organización social se suman las migraciones de la sociedad rural a la ciudad. Estos éxodos contribuyeron también a transformar sensiblemente la vivienda, abandonando la función 'escenográfica' que tenían hasta ese momento y adquiriendo un carácter más práctico y dinámico. Los nuevos trabajadores se trasladaban a las ciudades donde la falta de espacio motivaba la creación de tejidos residenciales en altura. Este aspecto limitaba inevitablemente las dimensiones de las viviendas, obligando a estudiar nuevas estructuras de vivienda con superficies mínimas pero que, sin embargo, debían cumplir con las cuestiones básicas y necesarias para poder disfrutar de la vida 'moderna'10.

Pero además las largas jornadas laborales a las que estaban sujetos los trabajadores no permitían más que el disfrute de la vivienda durante escasas horas, por lo que el mantenimiento de viviendas de grandes dimensiones carecía de sentido, especialmente, para trabajadores de clase media y solteros que desarrollaban sus actividades fuera del hogar. Esta situación favoreció la aparición de nuevas formas de vida que exigían una revisión de la vivienda, en cuanto a dimensiones y estructura. Los espacios reducidos procedentes de Europa comenzaron a aparecer con frecuencia en las páginas de las revistas como ejemplo de experimentación de la vivienda moderna.

Como consecuencia se abrieron dos campos de investigación de espacio doméstico: por un lado, la vivienda para nuevos roles sociales - como los apartamentos para solteros - que proclamaba la modernidad para las clases medias y altas; $y$, por otro, la vivienda mínima ${ }^{11}$ de carácter social diseñada para la clase trabajadora que fue objeto de estudio de importantes arquitectos como Le Corbusier, Gropius o May, además de constituir parte sustancial de los temas abordados en los Congresos Internacionales de Arquitectura Moderna (CIAM) que se celebraron a partir de $1928^{12}$, promovidos por el Comité Internacional para la Resolución de los Problemas Arquitectónicos Contemporáneos (CIRPAC).

Ya en 1918 el arquitecto alemán Hermann Muthesius publicó su libro Kleinhaus und Kleinsiedlung (Casa mínima y barrio mínimo), en el que hacía un análisis detallado del problema del que partiría el debate del CIAM de Frankfurt de 1929. En dicho congreso se abordaba el tema de la vivienda mínima desde la premisa de la existencia mínima. Es a partir de entonces cuando se inicia un proceso de desarrollo de las teorías basadas en el aprovechamiento mínimo, tanto a nivel de la agregación morfológica de las viviendas, como al nivel individual tipológico de cada unidad. 
Es revelador que el título del segundo CIAM, celebrado en Frankfurt, fuese Das Existenzminimum (el mínimo existencial), cuestión que se había convertido en prioridad en la Europa de la posguerra tras la Gran Guerra. De hecho, en el tercer CIAM, celebrado en Bruselas en 1930 y mencionado anteriormente, el tema de la vivienda mínima será recurrente. No obstante, aunque el tema de este congreso estaba dedicado a la división racional de la superficie, muchos de los discursos que se dieron estaban dirigidos a aclarar algunas aspectos relevantes sobre lo que debía ser un espacio doméstico de calidad y los factores que podían mejorar las unidades de vivienda, como lo atestigua la citada intervención de Gropius.

En este contexto, el tema de las viviendas de dimensiones limitadas fue abordado en el periodo de entreguerras también por arquitectos que, a título individual, quisieron colaborar con esta gran empresa aportando sus ideas a través de proyectos construidos. Este es el caso del arquitecto alemán Rudolf Fränkel ${ }^{13}$ —conocido también como Rudolph Frankel— quien profundizó en 1932 en el diseño de "Viviendas de una habitación", tal y como lo recogía la revista Viviendas. El artículo, que contenía dos proyectos de Fränkel, pretendía mostrar las posibilidades que este tipo de espacios permitían ${ }^{14}$. El proyecto, de gran simplicidad, consistía en la creación de una vivienda compuesta de un dormitorio unido al salón, un pequeño vestíbulo-cocina, un cuarto de baño y una terraza. Fränkel organizó el programa en tres franjas, dando lugar a un diseño que destacaba por su buen resultado funcional.

Dos años después, el mismo arquitecto propuso la manera de crear una vivienda con tan sólo dos habitaciones, partiendo de un esquema muy similar al anterior. En el "Piso de un soltero" se planteaba un nuevo modelo residencial que se ajustaba a los transformados hábitos cotidianos: "De solamente dos habitaciones consta este piso de soltero, que por otra parte son las necesarias y suficientes para la vida de un hombre solo, que por lo común hace sus comidas fuera de casa"15. La primera de las estancias era un recibidor que hacía también de cuarto de estar; constaba de una cama turca iluminada por un brazo de luz ajustable, una pequeña mesita donde poder colocar unas tazas de té, un secreter con escritorio y un armario para múltiples usos. La segunda era el dormitorio, con un espejo de pie para vestirse y un armario cómoda para el almacenamiento de trajes y calzado. El arquitecto explicaba que la sencillez y la fácil limpieza habían sido las dos cualidades determinantes para la elección y diseño de los muebles.

El edificio de apartamentos en el que se encontraba -Edificio de apartamentos Dr. Roth- era un edificio de lujo construido para el abogado Dr. Edmond Roth en la calle Alex. Lahonvary 8 de Bucarest. Aprovechando esta situación, Fränkel instaló su vivienda y estudio en el ático del edificio que él mismo había renovado. Se trataba de un proyecto de carácter experimental y expositivo de su arquitectura y su mobiliario ${ }^{16}$. La propuesta de Fränkel tenía su interés en la eliminación de los pasillos, lo cual permitía crear una tipología basada en la sucesión espacial de estancias. Mediante la supresión de puertas y tabiques logró obtener un espacio único y continuo que transformaba también la 
vivienda tradicional. El artículo titulado "La vivienda del arquitecto" describía cómo era el hogar del arquitecto mediante la narración de la distribución del mobiliario ${ }^{17}$.

También en Francia suscitó gran interés el estudio de la distribución y concepción de interiores. Los arquitectos Jean Ginsberg y Berthold Lubetkin ${ }^{18}$, que compartían la aspiración de adaptar la racionalización básica de Beaux Arts a la aplicación moderna, se unieron para realizar el proyecto del número 25 de la Avenida Versalles. Tras analizar la obra de Lubetkin recogida por John Allan ${ }^{19}$, parece que este proyecto fue el único en el que existe una preocupación prioritaria por la correcta distribución del interior y un interés por la realización de un mobiliario acorde. Varias revistas publicaron los interiores de una de las viviendas del edificio de nueve plantas, lugar donde también habían instalado su propia vivienda y estudio.

Bajo el título "Una vuelta alrededor de una habitación" la revista Viviendas mostraba la distribución del espacio principal, el estar, situado en el acceso de la vivienda. El artículo explicaba lo siguiente: "En realidad, está dividida en 3 departamentos: un pequeño recibidor, que puede ser aislado del resto por una cortina; un gran cuarto de estar, y un comedor separado del anterior, por un pequeño muro con cactus y chumberas." 20 En cambio, Obras. Revista de Construcción ${ }^{21}$, mostraba más imágenes del conjunto del edificio, pero también hacía hincapié en la configuración tripartita del departamento de los arquitectos. La división espacial en tres estancias era posible gracias al diseño de piezas de mobiliario: muebles-zócalo combinados con piezas producidas en serie.
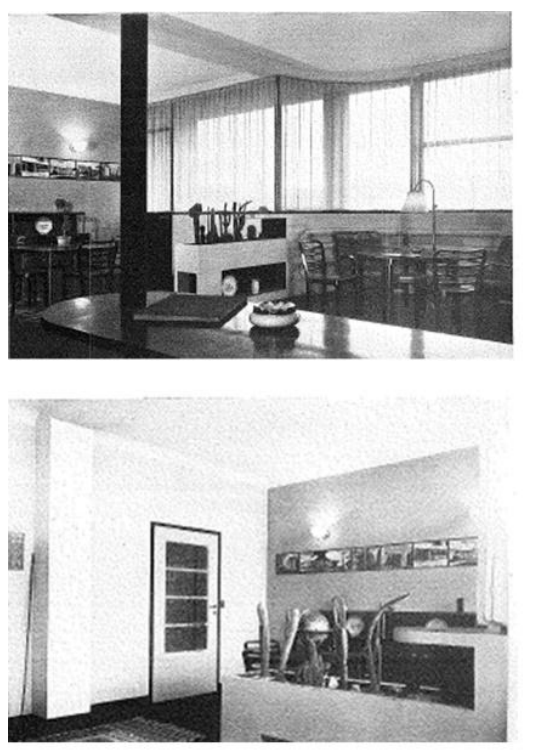
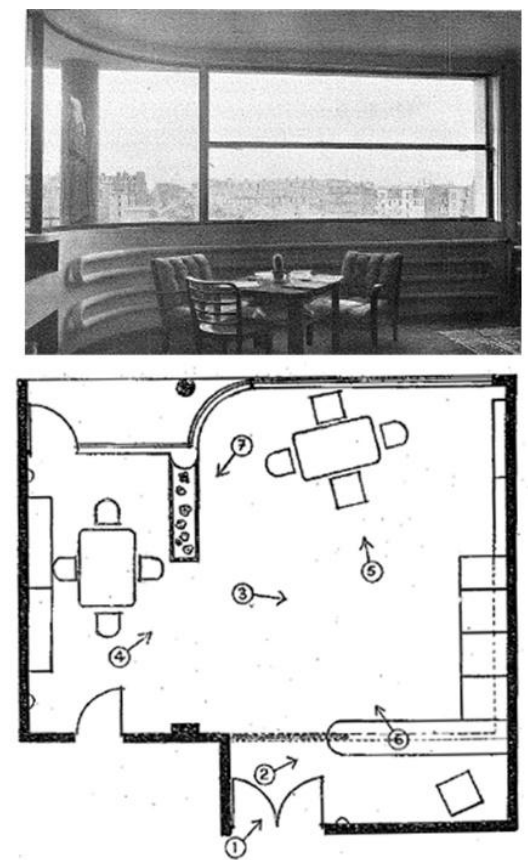
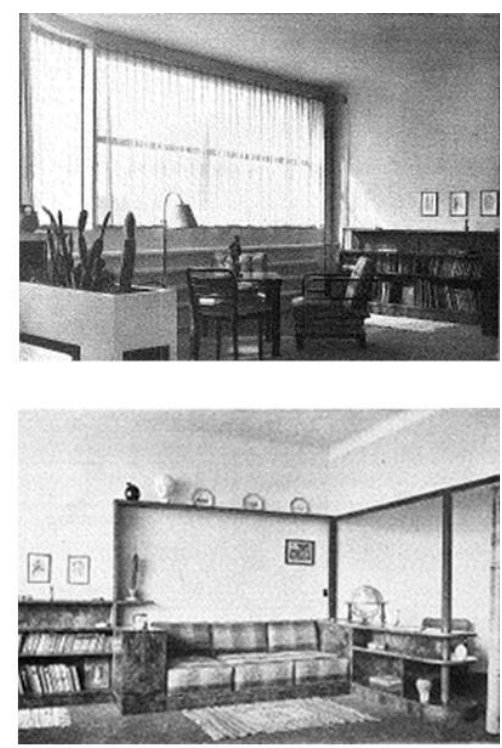

Fig. 3. Planta y fotografías realizadas desde distintos puntos de la estancia proyectada por Ginsbert y Lubetkin. Fuente: Viviendas. Revista del Hogar, nº4, Madrid, 1932, y Obras. Revista de Construcción, n³3, Madrid, 1934. 
Otro proyecto de carácter más dinámico pero igualmente multifuncional fue el de las arquitectas francesas Olga e Isabel Gémes, titulado "Transformación de un piso" 22 . Esta obra que partía de la adecuación de una antigua casa de campo, mostraba la versatilidad espacial que se podía alcanzar modificando la distribución del mobiliario. En la primera opción, el estar se convertía en comedor tan sólo con tres cambios: la estantería se cambiaba de posición, la mesa se ampliaba y las butacas se desplazaban hacia el ventanal creando un espacio para la conversación o lectura. El segundo, ofrecía una disposición más propicia para el trabajo; esta vez la mesa cerrada se ubicaba en la parte del ventanal, permitiendo liberar el espacio central y creando un estar. El mobiliario que constituía el ajuar de aquella arquitectura, era de acero y estaba combinado con piezas de madera. La doble disposición de los muebles en el cuarto de estarcomedor, permitían disfrutar de un espacio versátil con muchas distribuciones de la misma estancia.

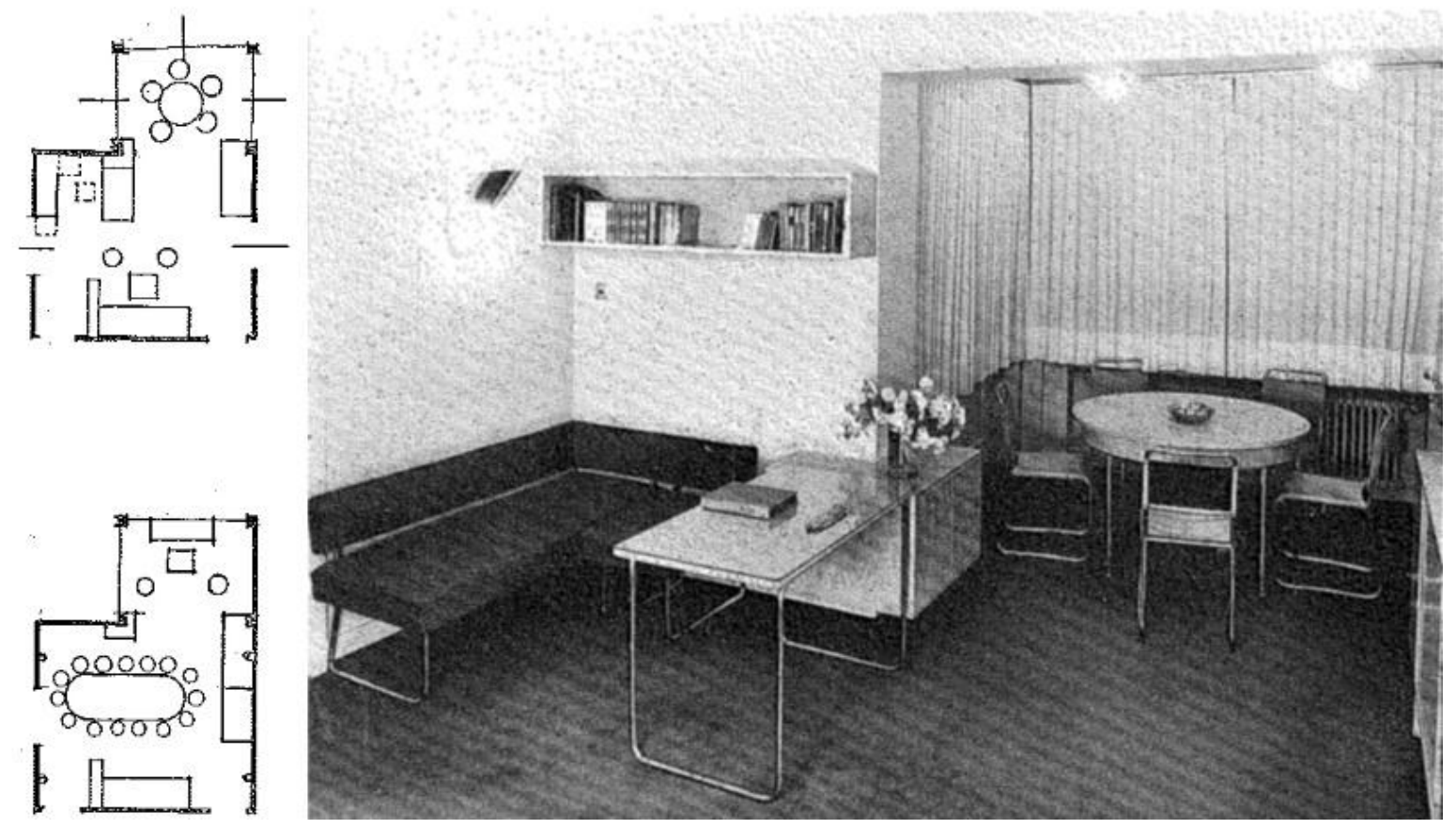

Fig. 4. Doble disposición y fotografía de los muebles del salón, proyecto de Olga e Isabel Gèmes. Fuente: Viviendas. Revista del Hogar, n³0, Madrid, 1934.

\section{Nuevas tipologías de muebles para espacios transformables}

Todos los esfuerzos dirigidos hacia la reducción y simplificación del modelo de vivienda hacían imprescindible la existencia de habitaciones con un doble fin o un doble uso y, en ocasiones, incluso varios. Esta situación propició una mayor investigación en el ámbito del mobiliario, haciéndose necesaria la creación de piezas que satisficiesen varias funciones. Por tanto, la renovación del espacio doméstico comenzaba por una reducción espacial y continuaba por una profundización en el estudio de las posibilidades del equipamiento del hogar ${ }^{23}$. Se daba lugar, así, por un lado, a piezas zócalo que se adherían a la arquitectura y 
aglutinaban distintos usos $\mathrm{y}$, por otro, a muebles transformables que desempeñaban diversos usos al modificar su forma.

Estas tipologías no sólo se caracterizaban por la movilidad del objeto en un determinado espacio, sino también la correcta distribución del mismo en la arquitectura. Pero además, existía otro tipo de movilidad que se producía en el propio objeto; el cual interactuaba con el espacio en tres dimensiones. Fue esta característica la que modificó el rumbo de la vivienda, sirviendo como campo de experimentación e ingenio para muchos diseñadores que vieron en la propia transformación del mueble una posibilidad de poder dotar a las pequeñas viviendas de mayor flexibilidad espacial.

Los avances más destacados en este campo fueron protagonizados por el arquitecto Pierre Chareau, el diseñador del mueble en movimiento ${ }^{24}$. Chareau se situó en Francia a la cabeza del grupo de artistas decoradores que pretendían liberarse de los estilos históricos, y apostar por la cualidad funcional del mobiliario, tal y como lo explicaba Fernando García Mercadal ya en 1928: "Lo práctico es por ellos más perseguido que lo bello"25. La originalidad de sus piezas, giratorias y plegables convertía a Chareau en el referente del mueble galo del momento. Sus interiores dirigidos al hombre moderno fueron diseñados a partir de formas claras y puras llenas de una limpieza excepcional y de materiales como la madera o el metal. El mobiliario del arquitecto francés fue elevado al plano de obra de arte por Mercadal, quien consideró que sus muebles eran "piezas de museo", debido a una extraordinaria precisión mecánica, y a una esmeradísima ejecución.

Pero, sin duda, la característica principal de la obra de Chareau era la movilidad física del mobiliario. Este rasgo distintivo quedó patente en su participación en la Exposición de las Artes Decorativas de París con sus bibliotecas giratorias y plegables, sus techos en abanico o sus mesas 'con truco'. El movimiento de las piezas de Chareau potenciaba la relación del mueble con el espacio arquitectónico, resolviendo, tal y como explicaba Remon, "una serie de problemas interesantes: la economía de la disposición de un interior, en función de las leyes de la higiene, la iluminación, las proporciones, la distribución del espacio." 26 

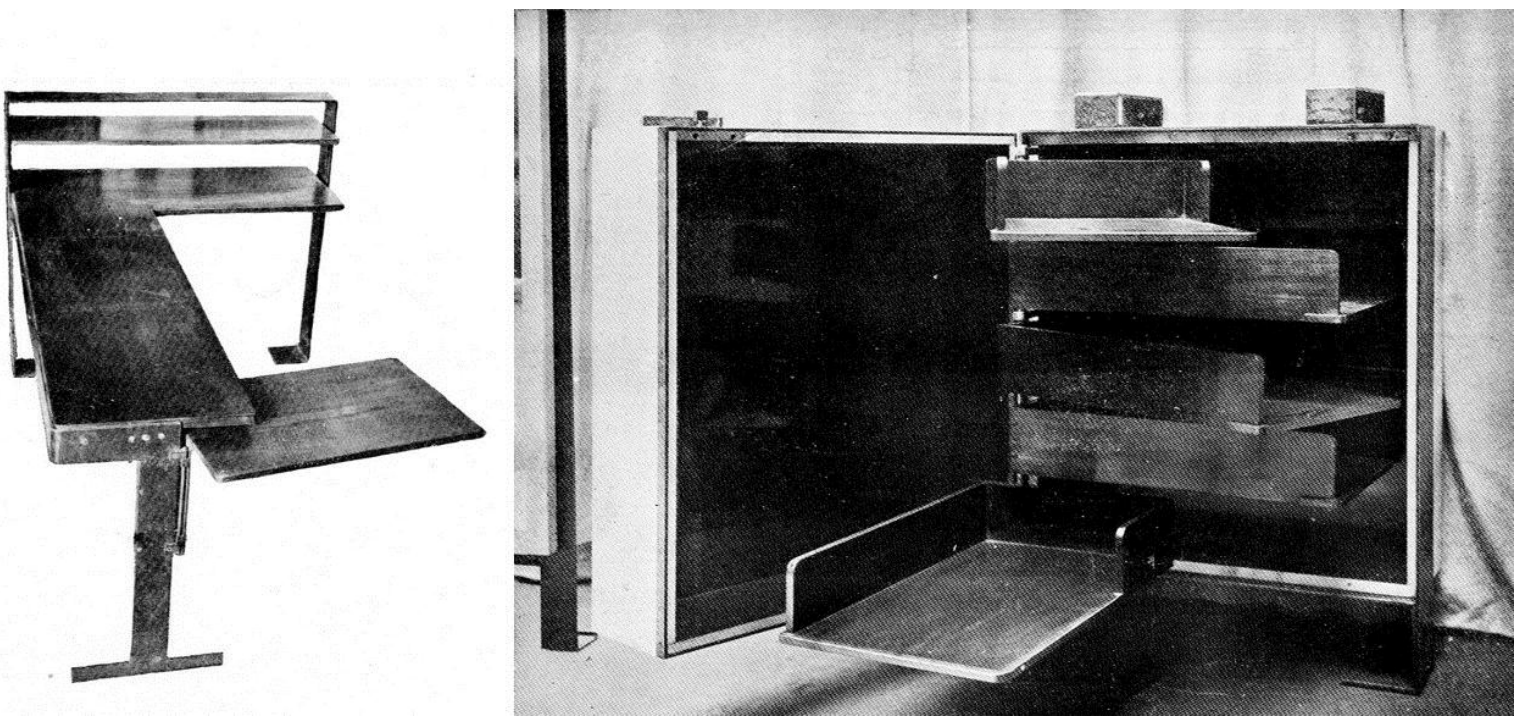

Fig. 5. Mobiliario diseñado por el arquitecto Pierre Chareau, publicado en 1928 por la revista Arquitectura.

Estas cualidades espaciales también fueron investigadas por otros arquitectos y diseñadores que apostaron por la creación de muebles-zócalo que, en ocasiones, incluían elementos móviles y resolvían distintas funciones en una sola pieza. Estos modelos, al igual que los de Chareau, debían contemplar en su diseño la movilidad de sus elementos para alcanzar una mayor versatilidad espacial. De hecho, esta tipología fue las más repetida en las publicaciones del periodo, tanto internacionales como nacionales, en las que se recogieron los proyectos de Paul Bry, Reudenauer o Barret, y que sirvieron de ejemplo e inspiración a otros arquitectos de la época.

Uno de estos proyectos fue la "Vivienda completa en un sólo cuarto"27 de Reudeneuer. Este proyecto consistía en diseñar un único mueble de formas curvas y rectas que se adecuaba correctamente a la exigencia de las nuevas viviendas: el máximo aprovechamiento en el mínimo espacio. Reudenauer ideó un mueble-zócalo de volumetría sencilla que satisfacía múltiples necesidades a la vez y que, además, reflejaba la intimidad y la armonía que se debían alcanzar en la casa. El mueble que se adhería al perímetro de la sala contenía un sofá cama, una cómoda, una mesa y distintos espacios de almacenaje, de modo que un único mueble transformaba la habitación en salón, estudio, dormitorio y comedor.

Pero quizás lo más significativo en este caso era cómo esta forma de equipar delataba su incipiente 'modernidad', que se adivinaba en sus obras, y que la revista Nuevas Formas describía del siguiente modo: "poseen una cualidad rara y preciosa: están vivificados del auténtico espíritu popular y se encuentran a la vez libre y naturalmente dentro de la casa, sirviendo las necesidades culturales del hombre moderno. Aquí el espíritu popular no retrocede buscando formas pasadas, formas antisociales y poco ciudadanas, por el contrario afirma todo aquello que se llama existencia moderna, su técnica y su ritmo. El observador de los muebles de Reudenauer siente... una impresión extraña. Parece como si ya conociera aquellas cómodas, aquellas sillas.”28 


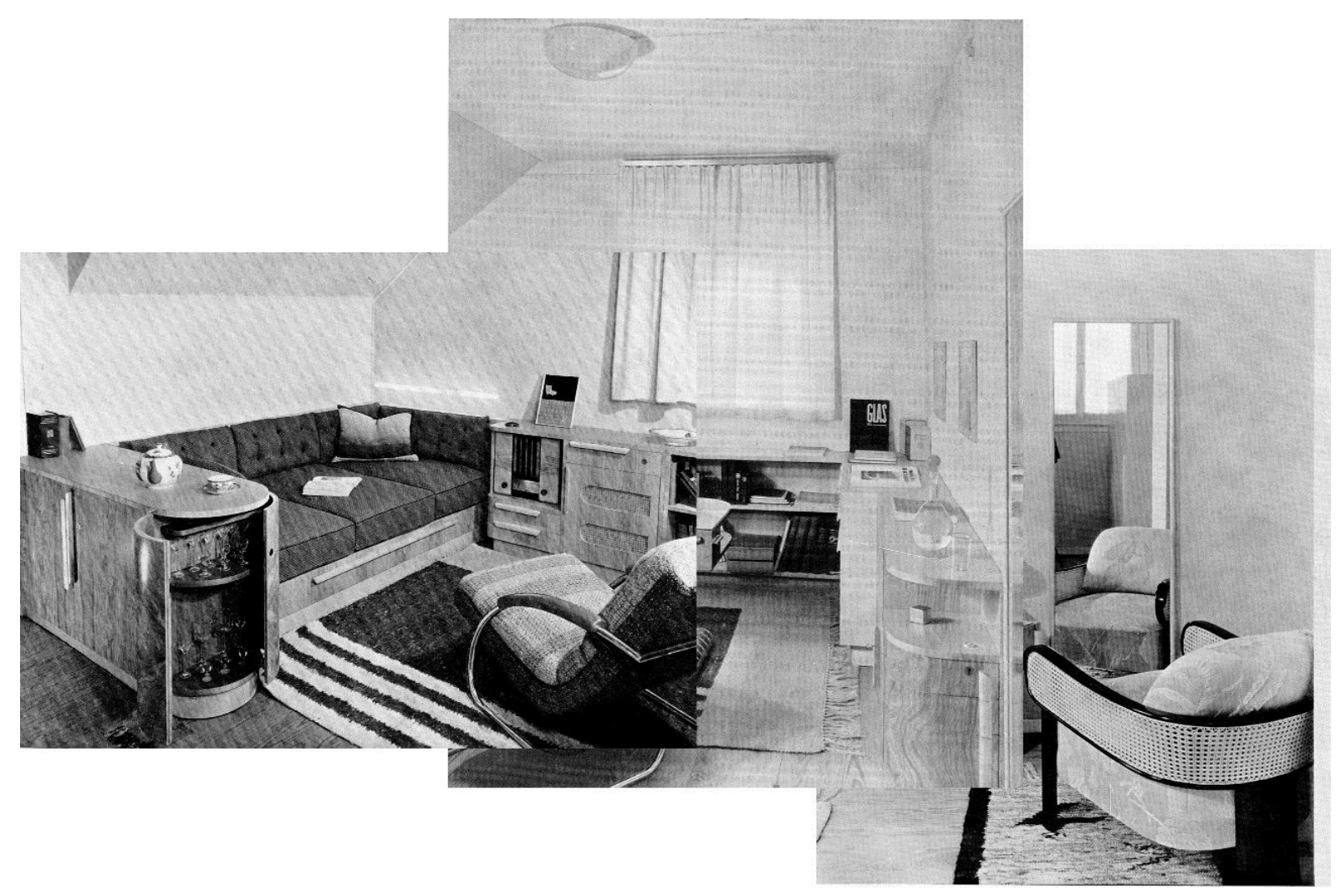

Fig. 6. Fotomontaje realizado por la autoría con fotografías de la "Vivienda completa en un solo cuarto", obra del arquitecto Reudenauer. Fuente: Nuevas Formas. Revista de arquitectura y decoración, n ${ }^{\circ}$, Madrid, 1935.

Otro diseñador destacado por su trabajo en la ideación de espacios transformables era el alemán instalado en Francia, Paul Bry²9. En 1935 y 1936, varios de sus proyectos diseñados para espacios polivalentes fueron publicados por varias revistas - Nuevas Formas, Viviendas y Obras-, posicionándose como uno de los diseñadores más destacados en este campo durante el periodo de entreguerras. En el proyecto "Tres habitaciones en una. Hogar de un soltero"30, Paul Bry hacía gala de su ingenio dotando a un sólo espacio de tres funciones diferentes. La vivienda se componía de una sola habitación que servía a la vez de alcoba, salón y gabinete de trabajo. Únicamente con cuatro piezas de mobiliario, el arquitecto disponía al servicio del usuario un espacio que cubría todas las necesidades propias de un soltero de la época, según explicaba el autor del artículo $^{31}$. 


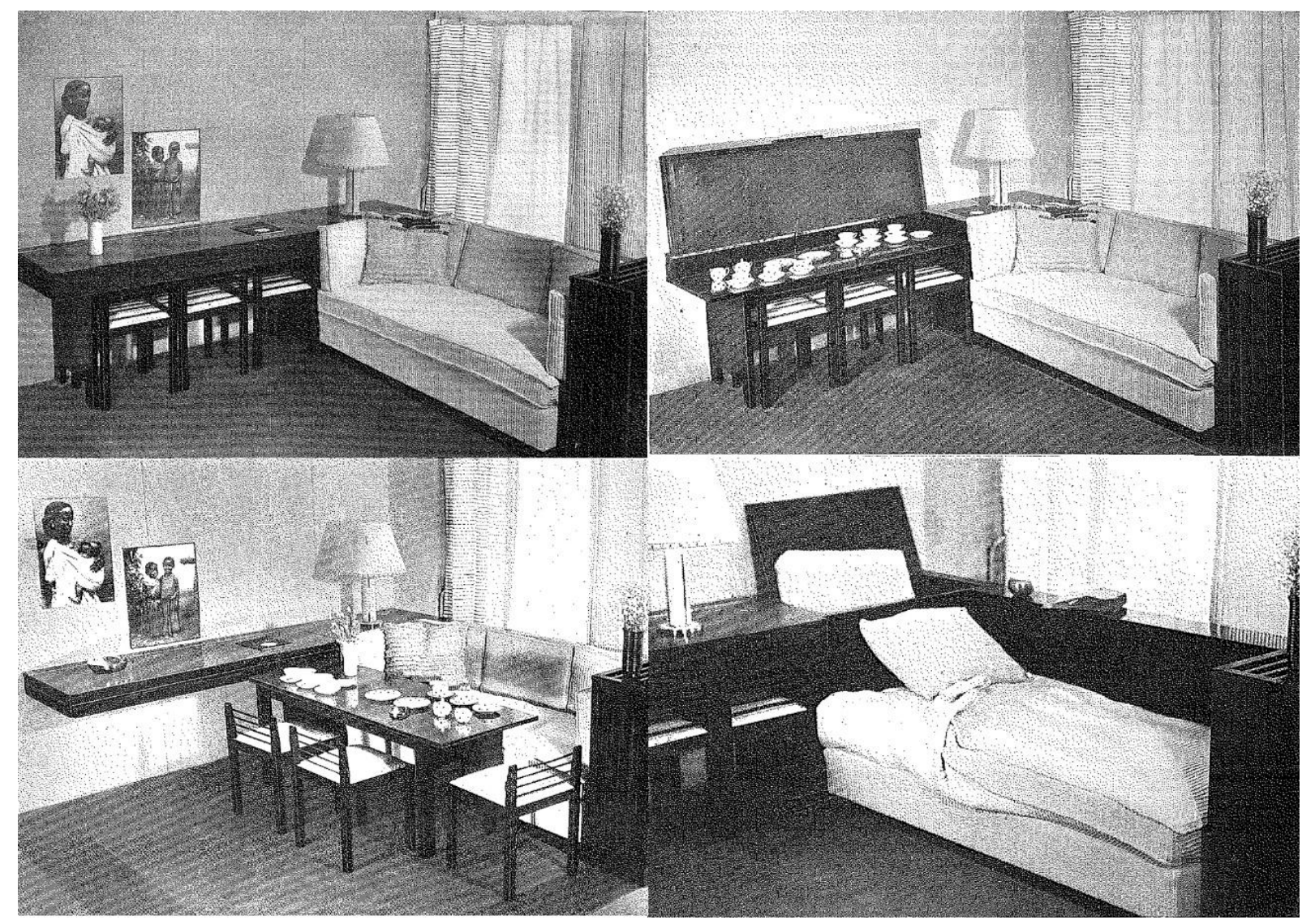

Fig. 7. Muebles transformables diseñados por Paul Bry para el proyecto "Tres habitaciones en una. Hogar de un soltero". En las imágenes se muestra la diversidad de funciones que cumplen sus piezas de mobiliario. Fuente: Viviendas. Revista del Hogar, n³8, Madrid, 1935.

Ese mismo año la revista Nuevas Formas volvía a publicar dos artículos de Bry sobre estancias transformables: "Un salón dormitorio" y "Una ventana práctica" 32 En el primero de ellos, el espacio servía a la vez de dormitorio, de gabinete de trabajo y de sala de estar: "Este salón lleva dos camas-divanes, colocadas juntas y formando ángulo recto [...] las sábanas se guardan en un armario lateral, el cual tiene las puertas de entramado de junco y de esta manera se airean durante el día. Este armario, así como uno de los divanes, llevan unas planchas diseñadas que al sacarlas sirven de mesitas de noche. Al lado del diván va un armario en forma de cómoda [...] La superficie de los muebles va cubierta con placas de resina sintética...se limpian fácilmente."33

En el segundo artículo, se presentó un proyecto en el que, como consecuencia de la escasez de espacio, Bry proyectó un mueble que desempeñaba dos funciones diferenciadas. Se trataba de una mesa plegable que estaba situada junto a la ventana y que, cerrada, permitía contener la vajilla y al abrirla servía de comedor: "Debajo van dos puertas correderas de $30 \mathrm{~cm}$ de altura. Detrás de estas puertas se oculta durante el día la mesa plegable y sobre una de sus mitades se coloca la vajilla preparada para la comida. A la hora de comer se tira de la mesa hacia fuera y se colocan los platos, vasos, etc. [...] una vez terminado se empuja todo adentro hasta que la dueña de la casa tenga ocasión de ocuparse 
de su limpieza [....] Todo esto es de una construcción sencilla y evidente. Se ha huido de toda mecánica [...]"34

Dos interiores muy semejantes a los publicados por Nuevas Formas fueron recogidos por la revista Obras. El artículo formaba parte de la sección "Interiores y Decoración" 35 que estaba, en este caso, dedicada a mostrar las obras de Paul Bry. Uno de los proyectos publicados consistía en un mueble para salón muy similar al proyecto del mismo autor anteriormente explicado - "Tres habitaciones en una"- que resolvía distintas funciones -almacenaje, comedor-salón y dormitorio- mediante un zócalo. El otro mostraba un juego de sofás que se transformaban en una cama doble que permitía dotar al espacio de una mayor flexibilidad, haciendo de salón en unas ocasiones, y de dormitorio, en otras. Este proyecto brillaba por una moderna versatilidad espacial derivada casi exclusivamente del ingenio del mueble de Bry.
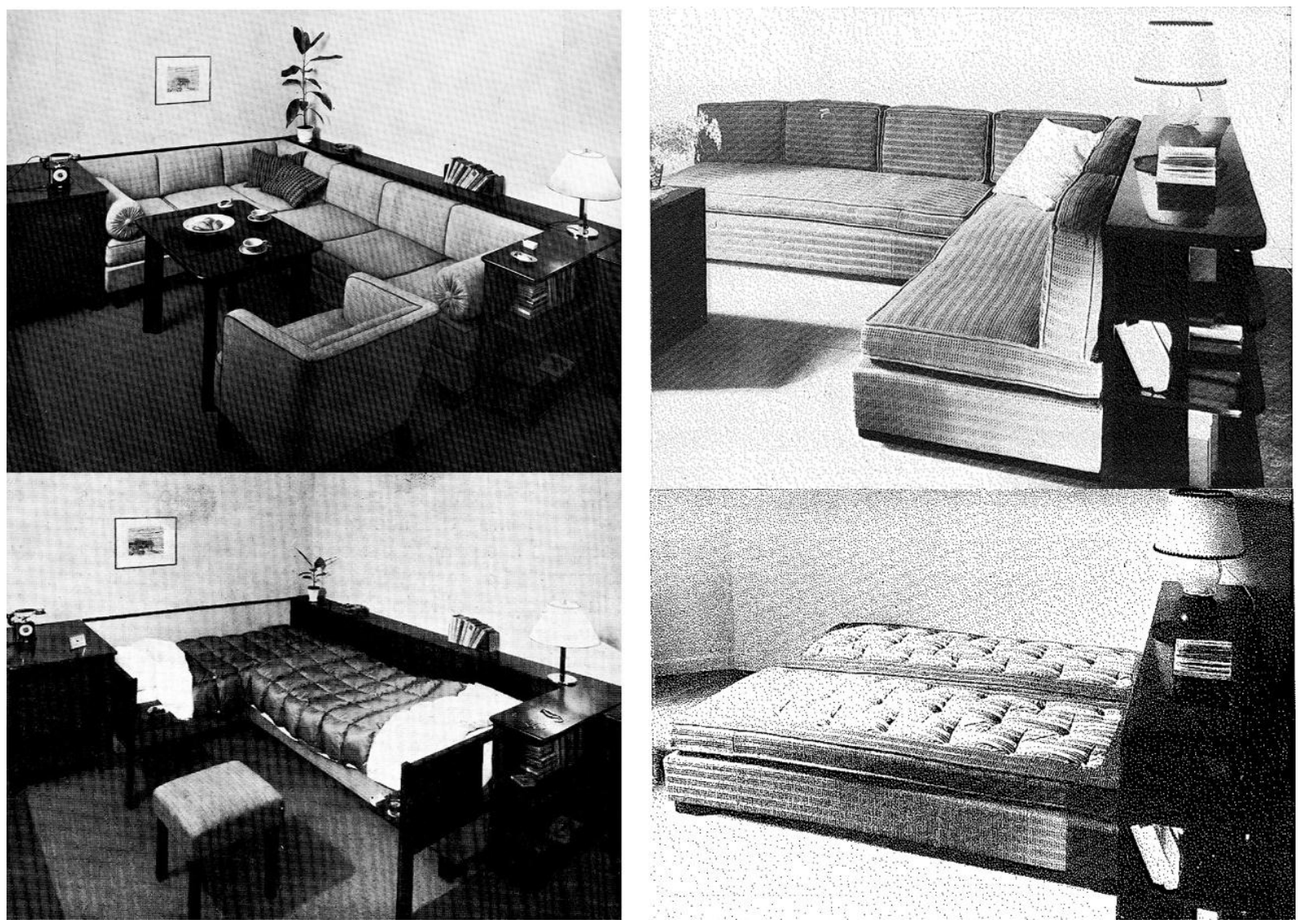

Fig. 8. Dos proyectos de Paul Bry: "Un salón dormitorio", y un sofá-cama. Flexibilidad de usos gracias al mobiliario transformable. Fuente: Nuevas Formas. Revista de arquitectura y decoración, nº1, Madrid, 1935 y Obras. Revista de Construcción, nº45, Madrid, 1936.

\section{Hacia un mobiliario moderno}

Tanto las obras de Bry y Reudenauer, flamantes ejemplos del aprovechamiento del espacio en un único mueble, como las piezas de Chareau, artefactos móviles que incluso lograban modificar la percepción espacial en su despliegue, son muestras del ingenio de estos creadores ante la reestructuración 
y redimensionamiento de la vivienda. Estas obras, al igual que las de Gémes, Ginsberg y Lubetkin o Fränkel sirvieron -y siguen sirviendo- como referente de la experimentación del amueblamiento de espacios reducidos y multifuncionales; y, por supuesto, de la capacidad de adaptación a los nuevos cambios sociales que se iban produciendo, - como la incorporación de la mujer al trabajo o el éxodo rural a las ciudades-, tal y como lo plasmaron en sus obras figuras como Reudenauer, Dobler o el destacado arquitecto Bruno Taut.

Estos proyectos, aunque no fueron los únicos, perfilan la evolución de la vivienda a través del mueble $\mathrm{y}$, como consecuencia, de la modernización de la sociedad. Los cambios sociales producidos tras la I Guerra Mundial repercutieron de forma directa en el diseño de mobiliario. Las nuevas formas de vida obligaron a reestructurar la vivienda y a reducirla, pero sin limitar sus posibilidades. La distribución y adecuación del hogar en el menor espacio posible se convirtió entonces en una de las preocupaciones de la época. Arquitectos y diseñadores investigaron el diseño del equipamiento de las viviendas para permitir una vida plena en dimensiones mínimas. Aspectos como la multifuncionalidad espacial, que en muchos casos no podían lograrse únicamente con la arquitectura, fueron objetivos prioritarios de los creadores que, casi sin darse cuenta, se encontraban por la vía de hecho produciendo nuevas tipologías de muebles.

Sin embargo, estos nuevos diseños no suponían exclusivamente un cambio formal o estético, sino que nacían de una voluntad de cambio que perseguía transformar la idea de mobiliario vigente hasta el momento. Ya no se trataba de un cambio superficial del lenguaje, sino un salto conceptual en la configuración del equipamiento basado en criterios funcionales que completaban la arquitectura. Lo que había comenzado como la respuesta a un problema de necesidades derivado de los cambios producidos por las nuevas formas de vida, terminó siendo una declaración de principios 'modernos' en favor del carácter práctico del mueble.

Se abandonaron las formas superfluas y ornamentadas, propias de los estilos, para adoptar nuevas tipologías de mobiliario, funcionales y adecuadas a las nuevas formas de vida de la clase media trabajadora. Esa practicidad, que se advertía en ese nuevo moblaje, delataba la modernidad de su diseño; un diseño moderno que, por otro lado, no sólo equipaba la arquitectura, sino que también formaba parte de ella y del proyecto de adecuación interior que ideaba el arquitecto. El mueble pasaba entonces a ser una parte fundamental de la obra construida ya que permitía dotar a la vivienda de cualidades espaciales, más allá de las decorativas, y que en ocasiones, debido a la pequeña escala, no estaban al alcance de la arquitectura.

La proliferación de apartamentos emergía como una oportunidad para la experimentación en el mobiliario con el objetivo de lograr un mayor aprovechamiento del espacio y sobrepasar los límites de lo construido. El diseñador encontró en el mueble una herramienta idónea para dotar al espacio de versatilidad, multifuncionalidad y confort, y proporcionar al usuario de una vida plena en una sociedad 'moderna'. El mobiliario se convirtió en elemento de 
experimentación con el que muchos arquitectos y diseñadores trabajaron logrando nuevos prototipos que cambiarían los modos de habitar.

De modo que los proyectos europeos de Reudenauer, Fränkel, Ginsberg, Lubetkin, Gémes, Chareau o Bry que presentan las nuevas tipologías de muebles móviles y transformables sirvieron para ilustrar ese cambio hacia la funcionalidad, ya iniciado en el mueble años atrás. Estos ejemplos de piezas adheridas a la arquitectura o equipamiento independiente surgidos de la necesidad de adaptación de la sociedad ante las nuevas formas de vida dejaban patente la importancia del diseño de mobiliario que permitía disfrutar de un habitar pleno en unas dimensiones mínimas. El equipamiento se convertía así en el catalizador de los cambios sociales en la vivienda, dotando al espacio mínimo de múltiples cualidades funcionales y superando los límites de la arquitectura; aspectos que, en definitiva, revelaban el camino hacia un mobiliario moderno.

\section{NOTAS}

\footnotetext{
${ }^{1}$ Las mujeres sustituyeron a los hombres en muchas de sus tareas, mientras ellos luchaban en la guerra: trabajaron en el campo, en la construcción, en las fábricas, como revisoras y conductoras de trenes y autobuses e incluso asumieron la dirección de distintas empresas. Cfr. MORALES, Maria Luz, La moda, siglo XX, 19001920, Barcelona, Salvat Editores, S. A., 1947; BOUCHER, François, Historia del traje en occidente, Barcelona, Gustavo Gili, 2009.

${ }^{2}$ MORALES, M. L., La moda, siglo XX, op. cit., p. 261

${ }^{3}$ TAUT, Bruno, Die neue Wohnung: die Frau als Schöpferin, Leipzig, Klinkhardt \& Biermann, 1924.

${ }^{4}$ El anuncio de este libro se había publicado en la sección "Revista de libros" dos años después de su aparición. Cfr. "Revista de libros: Die Neue Wohnung (la nueva vivienda), por Bruno Taut. 106 páginas con 65 ilustraciones editado por la casa Klinkhard, de Leipzig”, en Arquitectura, nº81, Madrid, 1926, p.32.

5 "Revista de libros", op. cit., p.32.

6 "Decoración de una vivienda dormitorio para una dama. Arq. Ernst Dobler", en Nuevas Formas. Revista de arquitectura y decoración, $\mathrm{n}^{\circ} 8$, Madrid, 1935/36, p. 424-428.

7 "Cuarto de estar para una dama. Arq. A. C. Reudenauer", en Nuevas Formas. Revista de arquitectura y decoración, n8, Madrid, 1935/36, p. 429-430; "Salón para la directiva de una fábrica. Arq. A. C. Reudenauer", en Nuevas Formas. Revista de arquitectura y decoración, nº, Madrid, 1935/36, p. 431-433.

${ }^{8}$ GROPIUS, Walter, “CConstrucción baja, media o alta?” en Aymonino, La vivienda racional : ponencias de los congresos CIAM 1929-1930, (version de J.F. Chico, J.M. Marco, J.C. Theilacker), Barcelona, Gili, 1976, p.223.

${ }^{9}$ GROPIUS, Walter, "Los fundamentos sociológicos de la vivienda mínima" en Aymonino, La vivienda racional : ponencias de los congresos CIAM 1929-1930, (version de J.F. Chico, J.M. Marco, J.C. Theilacker), Barcelona, Gili, 1976, p.114.

${ }^{10}$ MAY, Ernst, "La vivienda para el mínimo nivel de vida" en Aymonino, La vivienda racional: ponencias de los congresos CIAM 1929-1930, (version de J.F. Chico, J.M. Marco, J.C. Theilacker), Barcelona, Gustavo Gili, 1976, pp.108-113.

11 KLEIN, Alexander. Vivienda mínima 1906-1957, traducción Reinald Bernet, Jacint Conill y Miguel Usandizaga. Barcelona, Gustavo Gili, 1980.

${ }^{12}$ Para más información se recomienda consultar: MOLINA RAMÍREZ, Esteban, Orígenes de la vivienda mínima en la modernidad parámetros de calidad para la vivienda en las ponencias de los C.I.A.M 1929-1930, Tesis Doctoral, Universidad Nacional de Colombia Sede Medellín, 2014.

${ }^{13}$ Rudolf Fränkel nacido en Neisse, Silesia (ahora Nysa, Polonia) fue un judío alemán que estudió en el Royal Technical College en Charlottenburg y desarrollo su carrera profesional de preguerra en Berlín y Muchich, donde trabajo para arquitectos como Riemerschmid. En 1925 se convirtió en miembro del Deutcher Werkbund. Más tarde se trasladó a Bucarest, Londres y Estados Unidos, donde desarrolló su vocación docente en la Universidad de Miami, Ohio. Para más información se recomienda consultar: ZOHLEN, Gerwin, Rudolf Fränkel, die
} 
Gartenstadt Atlantic und Berlin: eine Ausstellung im Deutschen Werkbund Berlin, Niggli, Sulgen, 2006; BROWN-MANRIQUE, Gerardo, Rudolf Fränkel and Neues Bauen: work in Germany, Romania, and the United Kingdom, Tübingen, Wasmuth, 2009.

14 "Vivienda de una habitación, Rudolf Fränkel, Berlín”, en Viviendas. Revista del Hogar, n¹, 1932, p.11.

${ }^{15}$ FRANKEL, Rudolf, "Piso de un soltero", en Viviendas. Revista del Hogar, n²0, Madrid, 1934, p.20.

${ }^{16}$ Cfr. BROWN-MANRIQUE, Gerardo, Rudolf Fränkel and Neues Bauen: work in Germany, Romania, and the United Kingdom, cit.

17 "Un pequeño hall con sillones y un sofá cómodos, bar y armarito para tabaco sirve de recibimiento y salón de espera. De aquí se pasa directamente al estudio, separado del cuarto de estar comedor tan solo por una cortina. Las mesas de dibujo de roble negro sobre bastidor de tubo de acero, están colocadas a lo largo del ventanal orientado hacia el norte. En la pared del fondo vemos la librería empotrada, y debajo unos armarios para archivar planos. En la pizarra iluminada el arquitecto hace los primeros bosquejos para sus trabajos. [...] En el cuarto de estar comedor que el arquitecto utiliza también para celebrar en él consultas y reuniones, domina una mesa grande redonda con varios sillones cómodos. El aparador de nogal negro con tiradores de metal, está fijado en la pared.". "La vivienda del Arquitecto", en Viviendas. Revista del hogar, n45, 1935, p.74.

${ }^{18}$ Jean Ginsberg y Berthold Lubetkin se asociaron a finales de los años 20, pero en 1931, con la terminación de la obra, esta asociación finalizó. "L'habitation contemporaine" fue el único proyecto realizado por Lubetkin fuera de Inglaterra, donde ejecutaría obras como la del Zoológico de Londres que le situarían en lo alto de la arquitectura moderna.

${ }^{19}$ John Allan, autor de Berthold Lubetkin. Architecture and the tradition of the progress, analiza en este libro el proyecto analizado al que denomina L'habitation Contemporaine. A su vez este nombre correspondía al de la Société Civile L'Habitation Contemporaine que era la compañía de desarrollo para la ejecución del proyecto de la Avenida de Versalles 25. Cfr. ALLAN, John, Berthold Lubetkin. Architecture and the tradition of the progress, RIBA publications, Londres, 1992.

20 "Una vuelta alrededor de una habitación. Ginsberg y Lubetkin, París”, en Viviendas. Revista del Hogar, n4, Madrid, 1932, p.22.

21 "Casa de alquiler en la Avenida de Versalles, núm.25”, en Obras. Revista de Construcción, n³3, Madrid, 1934, pp.314-320.

22 “Transformación de un piso. Arqs. Olga e Isabel Gémes”, en Viviendas. Revista del Hogar, n³0, Madrid, 1934, p.24.

23 ARANGO FLOREZ, John, El Mueble como Estructurador del Espacio en la Vivienda Moderna. Tesis Doctoral, Universidad Nacional de Colombia, Sede Medellín, 2012.

${ }^{24}$ El título de El mueble en movimiento toma prestado su nombre de la publicación del catálogo de la exposición realizada sobre Chareau del 14 Octubre al 13 de Noviembre de 1993 en la Galerie Jacques De Vos, París.

${ }^{25}$ GARCÍA MERCADAL, Fernando, "El arte del mueble en Francia. Pierre Chareau", en Arquitectura, n¹14, Madrid, 1928, p.328.

${ }^{26}$ El texto original fue publicado en la revista en francés: “(...) un certain nombre de problemes interessant: l'economie de l'agencement d'un interieure, en function de lois de l'hygiene, de l'eclairage, des proportions, de la distribution de l'espace.". GARCÍA MERCADAL, Fernando, "El arte del mueble en Francia. Pierre Chareau", op. cit., p.329.

27 “Una vivienda completa en un solo cuarto", en Nuevas Formas. Revista de arquitectura y decoración, n 5, Madrid, 1935, p. 264.

28 "Una vivienda completa en un solo cuarto", op. cit., p.264.

${ }^{29}$ El alemán Paul Bry se trasladó a París en 1933 tras haber conseguido el título de abogado y posteriormente estudiar arquitectura en la Escuela de Artes Decorativas de Berlín. Fue allí, en la capital francesa donde realizó gran variedad de diseños de interiores de apartamentos y tiendas. En 1938, Bry se instaló en Nueva York y se asoció con otro diseñador de interiores, Joachim Hoffman hasta 1945, especializándose en el diseño de espacios mínimos y diseño modular propio de la post-guerra. La prensa tomó nota de la practicidad, confort y estilo contemporáneo de sus muebles; e incluso, Bry publicó varios libros sobre mobiliario, entre los que destaca: BRY, Paul, How to buid your own furniture, Macmillan, 1951. Asimismo, forma parte de monografías como la que se cita a continuación: ARCHITECTURAL FORUM, Design Decade 1930-1940, Time, Philadelphia, V 73, nº4, 1940 .

30 "Tres habitaciones en una. Hogar de un soltero. Arq. Paul Bry”, en Viviendas. Revista del Hogar, n³8, Madrid, 1935, p.26-27.

31 "Dos o tres habitaciones representarían un gasto considerable e innecesario de instalación y sostenimiento, puesto que su único habitante no está en casa durante todo el día. [...] La pieza es pequeña. No se ven en ella más que un diván y una mesa, a la que sigue un armario y una mesita junto a la ventana. [...] Debajo de la mesa 
se sacan tres sillas [...]. Entonces se abre la tapa de la mesa - lo mismo que un piano- y a nuestra gran sorpresa aparece una mesa servida [...] Termina la comida, se vuelve a ocultar la mesa en su sitio, evitando estar así rodeados de platos sucios. A la mañana siguiente mientras se está en la oficina la criada lo coloca todo en su sitio. La mesa cerrada tiene la altura de un pupitre. La placa de resina sintética no absorbe las manchas de tinta. El diván que por las noches sirve de cama, se tapa con una tela de algodón, fácilmente lavable. Toda la ropa de cama... se halla en una especie de arca o cajón situado al lado de la cama. Este cajón está provisto de aberturas especiales para la ventilación de la ropa". "Tres habitaciones en una. Hogar de un soltero. Arq. Paul Bry", op. cit., p.26-27.

32 "Un salón dormitorio. Paul Bry, decorador", en Nuevas Formas. Revista de arquitectura y decoración, nº 1 , Madrid, 1935; "Una ventana práctica. Paul Bry, decorador", en Nuevas Formas. Revista de arquitectura y decoración, $\mathrm{n}^{\circ} 1$, Madrid, 1935.

33 “Un salón dormitorio. Paul Bry, decorador", op. cit., p.50-51.

34 "Una ventana práctica. Paul Bry, decorador", op. cit., p.50.

35 “Interiores y Decoración. Arquitecto, Paul Bry”, Obras. Revista de Construcción, n45, Madrid, 1936, p.32-33.

Fecha de recepción: 18 de agosto de 2014

Fecha de revisión: 29 de septiembre de 2014

Fecha de aceptación: 3 de noviembre de 2014 